\title{
STEP UP THE HEAT: A REGRESSION DISCONTINUITY ANALYSIS OF THE EFFECT OF HOME HEATING SUBSIDY ON ENERGY EXPENDITURE
}

\author{
Jan-Jan Soon* \\ Universiti Utara Malaysia
}

\begin{abstract}
Using a recent housing survey micro level dataset, this paper estimates the causal effects of receiving a home heating subsidy on different types of energy expenditure. Applying a regression discontinuity design quasi-experimental framework, identification for the causal treatment effect of energy subsidy is achieved by exploiting exogenous variations generated from the subsidy eligibility rule. Results are obtained from three model estimations: first-stage, reduced-form, and second stage estimations. The main finding from each of these estimations are: (i) energy subsidy eligibility increases the probability of receiving the subsidy, (ii) subsidy eligibility decreases energy expenditure, and (iii) subsidy receipt decreases energy expenditure. For an eligible household, its probability of receiving the subsidy increases between 2 to 8 percentage points at the threshold. Just by virtue of being eligible, such households see an approximate $8 \%$ to $25 \%$ decrease in their total energy expenditure at the threshold. Households that receive energy subsidies decrease their total energy expenditure by about half to threequarters at the threshold.
\end{abstract}

Keywords: Energy Subsidy; HEAP; Energy Expenditure; Home Space Heating; Regression Discontinuity.

\section{INTRODUCTION}

\subsection{Overview}

According to the latest Residential Energy Consumption Survey conducted in 2009 by the U.S. Energy Information Administration, the total U.S. energy expenses amount to USD230 billion; average energy consumption per household is USD2,000. Households with an annual income in the USD20,000 to USD39,999 bracket have the highest energy expenditure of USD48 billion. Those in the USD40,000 to USD59,000 bracket come second at USD42 billion, and households in the lowest income group of the USD20,000 or less come third at USD37 billion. These 3 income groups make up about $72 \%$ of the total 113.6 million housing units in the U.S. in 2009. As for the type of energy consumed by the U.S. as a whole in 2009, natural gas and electricity have the highest consumption, followed by marginal consumption of fuel oil, propane/LPG, and kerosene. Space or home heating accounted for $63 \%$ of

- Corresponding author: Jan-Jan Soon is Senior Lecturer at University Utara Malaysia. Postal address: Economics Building, School of Economics, Finance \& Banking, University Utara Malaysia, 06010 Sintok, Kedah, Malaysia. Email: soon@uum.edu.my 
natural gas consumed in U.S. homes; the remaining 37\% was for water heating, cooking, and miscellaneous uses. A total of USD65 billion is spent on home heating expenses. This expenditure on home heating alone represents approximately $28 \%$ - the highest - from the total energy expenditure of USD230 billion. Based on the U.S. Energy Information Administration (EIA), in 2011, energy consumption by New York home end-users constitutes $29.6 \%$, second only to the commercial sector that consumes $32.7 \%$ of total energy. In 2009 , home heating in New York households makes up the largest portion of energy consumption, at $56 \%$. Other energy consumption includes those for appliances and electronic usage at $26 \%$, water heating $(17 \%)$, and air-conditioning (1\%).

In the U.S., home energy consumption is mainly subsidized by a federal program known as the Home Energy Assistance Program, or the HEAP subsidy for short. The U.S. National Energy Assistance Directors' Association (NEADA) reports that the funding for HEAP has declined between 2010 and 2013 from USD5.1 billion to USD3.3 billion. NEADA also estimated that during that period, due to the budget cut for HEAP funding, the number of households served by the HEAP subsidy declined from 8.1 to 6.7 million households nationwide. The budget cut in the HEAP funding for New York during that period sees a decrease from USD537 million in 2010 to USD350 million in 2013. Earlier in 2014, a further reduction of the federal budget in the appropriation for HEAP subsidy has been proposed by the Obama administration for the 2014 fiscal year, despite the fact that the country is still recovering from the recent cold spells especially in the northern part of the country where New York is. Little is known empirically on the causal effect of the HEAP subsidy on energy expenditure. With such high fiscal cost of providing energy subsidy, it is important to know if such subsidy is in fact lowering targeted households' energy expenditure. If so, then the aim of the subsidy is achieved. This is the study's main purpose.

In New York, the HEAP subsidy is administered by the State Office of Temporary and Disability Assistance. The subsidy aims to assist low-income households in meeting their home heating and energy expenditure. Eligibility to apply for the subsidy is based on household income, household size, primary heating source, and the presence of a household member who is less than age 6 , more than age 60 , or permanently disabled. The HEAP subsidy is given out as one of the following types: (i) a regular benefit to lessen the burden of the home main heating source expenses, (ii) an emergency benefit to assist with heat-related emergencies such as disconnected heating services, and (iii) a repair and replacement of heating equipment benefit. An eligible household may receive one regular HEAP benefit per program year. The subsidy is a one-off annual benefit paid directly to authorized utility companies or the fuel vendors supplying the household's primary source of heat.

\subsection{Relevant literature}

Most literature on energy focus on energy consumption (and thus its expenditure) and energy efficiency. These two are related, in which energy consumption reduces when energy efficiency (the investment in it) increases. Dieckhoner (2012) hypothesized that energy subsidies can decrease energy consumption by increasing the quality of investments in energy efficiency, which she termed quality effect. She found that for tenant households, a $10 \%$ increase in 
energy prices (i.e. due to drop in energy subsidy) reduces energy consumption by $7.5 \%$. She concluded that owner households invest more in energy efficient modernization and thus decrease their heating expenditure.

A large part of the literature on the determinants (in which some of the studies also used energy subsidy as one of the determinants) of energy consumption have been analysed using time-series or a macro approach (Belloumi 2009; Li et al 2014; Mozumder \& Marathe 2007; Yuan et al 2010; Lin \& Jiang 2011; Halicioglu 2007; Holtedahl \& Joutz 2004; Lin \& Li 2012). While these macro type of studies are important in providing the bird's eye view of energy consumption issues at the country or state level, studies at the household micro level are also as important in ironing out factors that affect the households and the extent of the effects. Energy subsidies affect energy consumption, energy use efficiency, and the choice of fuel source (Lin \& Jiang 2011). They concluded that reducing or removing energy subsidies would increase energy prices, which in turn would encourage energy conservation. There are a number of other studies that support energy subsidies reduction or elimination in order to reduce consumption of energy from fossil fuel, to improve on energy conservation and to correct market distortions (Kebede 2006; Olivia \& Gibson 2008; Saboohi 2001).

Studies at the micro level looking specifically at the relationship between energy subsidies and energy consumption include the following. Using a household level data from a national survey and primary survey, Rao (2012) and Gangopadhyay et al (2005) looked at the impact of kerosene subsidies in India on the demand for kerosene fuel; they found the subsidies to be regressive to the rural poor but progressive to urban households. Their findings lauded those found by Freund and Wallich (1997) in which they also concluded energy price subsidies to be regressive for Polish households, especially in the consumption of gas fuel. Using sectoral level dataset, Saboohi (2001) looked at the impact of reducing energy subsidies on households' living expenses in Iran. Results showed that energy subsidy reduction would increase living expenses of both rural and urban households due to higher energy prices. A similar study by Kebede (2006) however, found that on the contrary, energy subsidies do not have any significant impact on households' purchasing power in urban Ethiopia. Using household level data, Olivia and Gibson (2008) found that a 10\% increase in kerosene price (due to subsidy reduction) to bring about a $13.3 \%$ decline in kerosene consumption by the rural households, and a $6.4 \%$ decline by urban households. Using a household level customer billing database from the Zimbabwe Electricity Supply Authority, Dube (2003) found that if energy subsidies were removed, electricity expenses by the extremely poor households would increase to $77 \%$ and the moderately poor to $87 \%$. These studies however do not use the potential outcome framework in estimating the causal effect of energy subsidies on energy consumption.

\subsection{Objectives and contribution of study}

This study's interest in the impact of energy subsidies on energy consumption is motivated in part by the many disparate and often contradictory empirical findings in the energy literature. As we have seen from some of the literature reviewed earlier, while some findings conclude energy subsidies to increase energy expenditure, others conclude otherwise. Moreover, the effect of energy subsidies on energy consumption using a treatment evaluation framework is 
not very well investigated. The study's main focus therefore is to estimate the causal effect of a home heating subsidy on energy expenditure. In the course of estimating this effect, this study also looks into the effect of subsidy eligibility on the probability of receiving the subsidy, and on energy expenses.

By combining a relatively recent dataset with the use of a regression discontinuity design (RDD), this paper contributes to the literature by estimating the causal effect of home heating subsidy (specifically, the HEAP subsidy) on energy expenditure. The contribution is especially relevant since there seems to be a lack of empirical studies dealing with this topic within a causal inference framework, especially one using a quasi-experimental set-up. The public policy question of interest is on the extent to which the actual receipt of a home heating subsidy affects energy expenditure.

\section{DATA AND METHODOLOGY}

\subsection{Data}

Data from the latest 2011 New York City Housing and Vacancy Survey (NYCHVS) are used. The main purpose of the NYCHVS is to determine New York City's vacancy rate, housing quality and quantity, as well as the residents' demographic characteristics. The survey was conducted between January to May 2011, with a total of 16,358 households surveyed. Information asked in the NYCHVS survey are for the year 2010. The households are selected from the 5 boroughs in New York. The NYCHVS dataset provides vital information on the key variables used in this paper: (1) whether or not a household receives the HEAP subsidy; this question has just been included in the 2011 NYCHVS questionnaire and was not asked in previous waves; this information would make up the treatment variable for the estimation method used in this paper, (2) household income and number of household member; these information would be used to construct the normalized household income since households of different sizes have a different threshold income to be eligible for the HEAP subsidy; the normalized household income would make up the assignment variable, (3) different types of energy expenditure such as consumption of natural gas, electricity, other type, and total energy; these would make up the outcome variables.

\subsection{Fuzzy RDD}

An RDD is a quasi-experimental design, where the probability of receiving treatment is a discontinuous function of an underlying variable. In this study, the RDD is triggered by exploiting the HEAP eligibility rule. Households with income below a certain threshold income are eligible to apply for the subsidy. This paper exploits random variations in receiving 'treatment' (i.e. receiving the subsidy) generated by the exogenously determined threshold income. The random variation arises as a consequence of the households' inability to precisely control or manipulate their income in the neighbourhood of the threshold income. Such variations in 'treatment' around the threshold are seen as randomized as though coming from a randomized say, coin-flip experiment (Lee and Lemieux, 2010). 
In a fuzzy RDD, as opposed to a sharp RDD, some observations that meet the threshold value are not given treatment and vice-versa. A fuzzy RDD is used in this study since there are eligible households that do not apply for the HEAP subsidy, i.e. there is imperfect compliance of the eligibility rule. The corresponding probability of getting 'treated' (receiving subsidy; $D=1$ ) is therefore a discontinuous function of the assignment variable $(X)$ at the threshold, i.e. $0<\operatorname{Pr}[D$ $=1 \mid \mathrm{X}]=\operatorname{Pr}[H E A P=1 \mid \mathrm{X}]=F(X)<1$. The assignment variable is the normalized household income. The key identifying assumption in a fuzzy RDD is that $F(\cdot)$ is discontinuous at the threshold value, so that there is a discontinuity in the probability of treatment at the threshold (Wooldridge 2010, p. 957). Such a discontinuity is clearly shown in Figure 1, plotted from the NYCHVS data.

Figure 1: Probability of Receiving Heap Subsidy

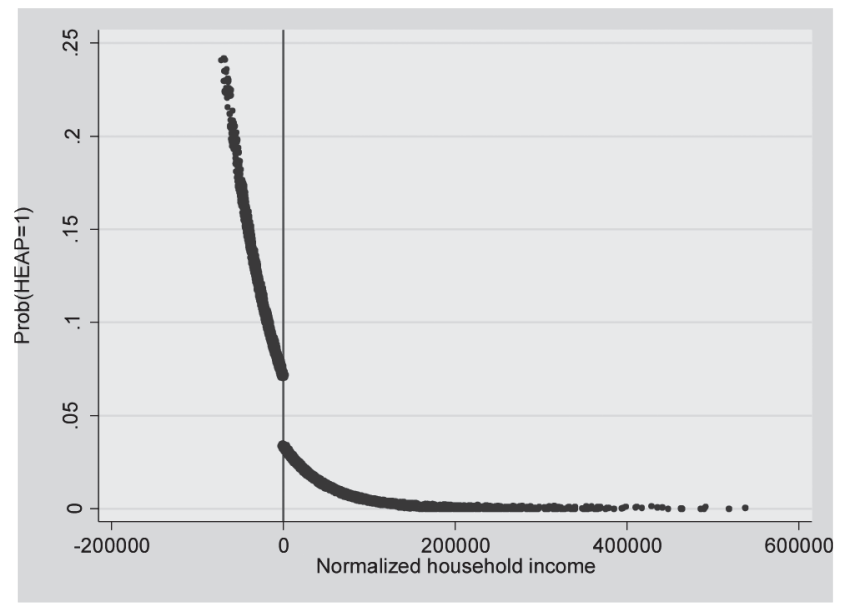

\subsection{RDD identification and estimation}

This section discusses the identification strategy used to estimate the causal treatment effect of subsidy on household energy expenditure. By identification of the treatment effect, it means that the discontinuity at the threshold income identifies the treatment effect of the HEAP subsidy. The main problem in identifying such an effect is that households that received the subsidy are not a random group, i.e. self-selection might be present. A naïve OLS estimation of such an effect between households that receive the subsidy and those otherwise, would produce an inconsistent estimate of the subsidy effect. Subsidy receipt is an endogenous variable due to systematic differences between households receiving the subsidy and those that do not. To estimate the causal effect of a subsidy on energy consumption requires taking into account self-selection bias. Such bias arises because households that receive the subsidy might have unobserved characteristics that are correlated with energy expenditure.

One way to circumvent the potential endogeneity bias is to exploit exogenous variation in the likelihood of receiving an energy subsidy. In this paper, the exogenous variation is generated 
by the eligibility rule predetermined by the authority on which households qualifies for the HEAP subsidy. Eligibility is based on a threshold annual household income and household size, with each household size having a different threshold income. The identification of the subsidy treatment effect is effectively triggered by this exogenously determined eligibility rule. Identification is achieved because the households in the immediate vicinity of the threshold income are deemed similar, i.e. households just to the left and just to the right of the threshold income have essentially similar characteristics that affect energy consumption. Any differences in their energy consumption is therefore interpreted as the causal effect of the HEAP subsidy. That is the main intuition behind the quasi experimental RDD.

As pointed out by Angrist and Lavy (1999) and Hahn et al. (2001), the fuzzy RDD is basically an instrumental variable (IV) estimator in which estimation is done using a two stage least square (2SLS). This study uses the HEAP subsidy eligibility as the instrument (Z), as shown in equation (1), to tease out endogenous variations in the treatment variable of interest, i.e. receipt of the HEAP subsidy. This constitutes the first stage of the 2SLS estimation. The instrument is uncorrelated with the error term in the outcome equation because subsidy eligibility is exogenously determined. The second stage as in equation (2), the outcome variable - energy expenditure - is regressed on the treatment or here, the actual receipt of subsidy (D), thereby obtaining unbiased causal estimate of the effect of subsidy receipt, i.e. the treatment effect of interest, $\delta$. Equation (3) is the reduced form equation, where $\rho$ measures the impact of the HEAP subsidy eligibility on energy expenditure.

First stage: $D=\lambda Z+g(X)+\gamma W+\eta$

Second stage: $Y=\delta D+f(X)+\beta W+\varepsilon$

Reduced form: $Y=\rho Z+h(X)+\tau W+v$

where,

$Z=$ subsidy eligibility; the instrument for HEAP subsidy receipt, i.e. $Z=1\left[X \leq X_{c}\right]$

$\mathrm{D}=$ binary treatment variable of interest, i.e. HEAP subsidy receipt

$\mathrm{X}=$ assignment variable, i.e. normalized annual household income

$\mathrm{W}=$ controls/covariates

$\mathrm{Y}=$ outcome variable, i.e. types of energy consumption

\subsection{Instrument, $Z$}

Subsidy eligibility is used to instrument subsidy receipt, i.e. $Z=1\left[X \leq X_{c}\right]$. The instrument $Z$ is a dummy variable indicating eligible households with income below the threshold income $X_{c}$. Eligibility is exogenously triggered by an administratively predetermined annual threshold household income. In 2010, a household of size one with annual income less than USD25,548 is eligible for the HEAP subsidy. Not all eligible households however, applied for and received the subsidy. Since the dataset does not distinguish between application and receipt, it is assumed here that households that applied for the subsidy received it. 


\subsection{Treatment variable, $D$}

The binary treatment variable of interest is whether or not a household receives the HEAP subsidy. This is the primary effect of interest; its coefficient $\delta$ measures the impact of receiving a HEAP subsidy on energy expenditure. A better measurement would be to use the actual amount of subsidy received, but there are some complications in using this as a (continuous) treatment variable. First, out of the 968 households receiving the HEAP subsidy, there are 103 households receiving a subsidy amount of USD1. These are households living in government subsidized housing units or state operated community residences in which heating cost is already included in the rent. Using the actual amount of subsidy received would therefore underestimate its impact. Second, some of the actual subsidy amounts have been top coded in the NYCHVS dataset. There are 27 households receiving an amount of HEAP subsidy which is above the top coded amount, with an average subsidy of USD1,266. There are also 77 households that received the subsidy but do not report the actual amount received. Due to these complications, using the actual subsidy amount could distort the estimates. The binary treatment variable is therefore used instead.

\subsection{Assignment variable, $X$}

The assignment variable used is the normalized annual household income. Since households with different household sizes have different eligibility threshold values, the household incomes are normalized to obtain more power for statistical tests. Separate analyses for households with different sizes would otherwise have too few observations. By pooling and normalizing the household incomes, such multiplicity of thresholds offers a certain degree of external validity to the subsequent findings since the results are not restricted to only one particular (absolute) threshold income (De La Mata 2012). There might be potential concerns about the endogeneity issue with regards to using household income as the assignment variable, as one expects that households are able to manipulate their income to meet the threshold income to be eligible for the subsidy. This concern is unwarranted for the following reasons. First, even though the households applying for the subsidy have knowledge of the threshold incomes, the thresholds are subject to change depending on the federal fund allocation to the HEAP. Therefore, the households would be unable to precisely control their eligibility for the subsidy. Second, empirical evidence from a subsequent validity check provides further reassurance that using household income as the assignment variable is sufficiently justified. Any prior concerns over the endogeneity of household income should now be adequately addressed, although its possibility cannot be entirely precluded. Any interpretations of the findings here should therefore bear this caveat in mind.

\section{RESULTS AND DISCUSSION}

\subsection{Summary statistics}

Table 1 shows the annual threshold income by household size to be eligible for the HEAP subsidy. These threshold incomes are extracted from the 2010-2011 HEAP Manual. The mean annual incomes and number of household are obtained from the 2011 NYCHVS dataset. Slightly more than $60 \%$ of the sample households from the 2011 NYCHVS consist of one 
and two household members. This proportion is quite similar with that of the 2009 U.S. Home Energy Consumption Survey in which its proportion of households of size one and two is $67.1 \%$. For the estimation purpose of this study, the different annual threshold incomes are normalized, as explained in the earlier section.

Table 1: Threshold Income Statistics

\begin{tabular}{ccccc}
\hline $\begin{array}{c}\text { Household } \\
\text { Size }\end{array}$ & $\begin{array}{c}\text { Annual threshold } \\
\text { income, } \mathbf{\$}\end{array}$ & $\begin{array}{c}\text { Mean annual } \\
\text { income, } \mathbf{\$}\end{array}$ & $\begin{array}{c}\text { No. of household, } \\
\boldsymbol{n}\end{array}$ & \% \\
\hline 1 & 25,548 & 38,232 & 5219 & 31.9 \\
2 & 33,409 & 70,652 & 4805 & 29.4 \\
3 & 41,270 & 71,705 & 2755 & 16.8 \\
4 & 49,130 & 82,124 & 1985 & 12.1 \\
5 & 56,991 & 71,098 & 894 & 5.5 \\
6 & 64,852 & 75,874 & 398 & 2.4 \\
7 & 66,326 & 62,605 & 179 & 1.1 \\
8 & 67,800 & 60,955 & 65 & 0.4 \\
9 & 69,274 & 73,697 & 37 & 0.2 \\
10 & 70,748 & 108,011 & 9 & 0.06 \\
11 & 72,345 & 73,233 & 9 & 0.06 \\
12 & 77,955 & 39,000 & 1 & 0.01 \\
\hline
\end{tabular}

Source: 2010-2011 HEAP Manual and 2011 NYCHVS dataset

As shown in Table 2, out of the 16,358 occupied households surveyed, only about $6 \%$ applied for and received the HEAP subsidy. The majority did not apply for this subsidy, while about $10 \%$ of the sample did not report on this item. There are 7,110 eligible households who did not receive the HEAP subsidy; these are referred to as the 'no show' in the program evaluation jargon. There are 862 'crossover', i.e. ineligible households that received the subsidy. Remaining are the 'compliers', i.e. eligible households that received the subsidy and ineligible households that did not. A Chi-squared test between subsidy eligibility and receipt (excluding the 'Unreported' category) shows a statistic of 611.2 with a p-value that is significant at the $1 \%$ level, suggesting a significant relationship between the subsidy eligibility and subsidy receipt categories.

Table 2: Heap Receipt and Eligibility

\begin{tabular}{ccccc}
\hline & \multicolumn{3}{c}{ Receipt of HEAP subsidy } & \multirow{2}{*}{ N } \\
\cline { 2 - 4 } & No & Yes & Unreported & \\
\hline Eligible & 7,110 & 106 & 811 & 8,027 \\
Ineligible & 6,547 & 862 & 922 & 8,331 \\
$n$ & $13,657(83.5 \%)$ & $968(5.9 \%)$ & $1,733(10.6 \%)$ & $16,358(100 \%)$ \\
\hline
\end{tabular}

Source: 2011 NYCHVS dataset 
Table 3 shows the different types of energy expenditure and household characteristics between households receiving the HEAP subsidy and those otherwise. The household characteristics are also used as control variables. Significant p-values indicate significant difference between the two categories of households.

Table 3: Summary Statistics

\begin{tabular}{lccc}
\hline & With HEAP & Without HEAP & p-value \\
\hline Types of energy expenses & & & \\
Natural gas (monthly, \$) & 83.0 & 101.8 & 0.001 \\
Electricity (monthly, \$) & 101.5 & 110.3 & 0.002 \\
$\quad$ Miscellaneous type (annually, \$) & 2034.9 & 3027.6 & 0.022 \\
$\quad$ Total energy (monthly, \$) & 139.1 & 147.3 & 0.024 \\
Household characteristics & & & \\
$\quad$ Age of house (years) & 14.9 & 13.7 & 0.006 \\
House purchase price (\$ ‘000) & 389.7 & 470.6 & 0.420 \\
Monthly mortgage payment (\$) & 1760.2 & 1901.5 & 0.261 \\
Fire \& Liability Insurance (annually, \$) & 952.5 & 1075.1 & 0.242 \\
Water \& Sewer Cost (annually, \$) & 975.8 & 922.4 & 0.358 \\
& & & \\
Number of observations, $n$ & 968 & 13657 & \\
\hline
\end{tabular}

Source: 2011 NYCHVS dataset

\subsection{Graphical analysis}

Graphical representations of the RDD provide an intuitive check if there is indeed any discontinuity or a jump at the threshold income. A discontinuity seen on a graph can be further validated by formal statistical tests. If there is no visual evidence of a discontinuity in a graph, it is then unlikely the formal regression methods will yield any significant treatment effects (Lee \& Lemieux 2010, p. 308; Imbens \& Wooldridge 2009, p. 64). The graphs in this section therefore serve as a preliminary overview of whether or not the receipt of a HEAP subsidy has any impact on energy consumption. Figure 2 shows the average expenditure for four types of energy (i.e. the different outcome variables, $Y$ ), plotted against the normalized household income (i.e. the assignment variable, $X$ ). Each graph is plotted using linear, quadratic, and cubic functions of the normalized household income.

A quick eyeballing of Figure 2 suggests that the HEAP subsidy seems to have an impact on total energy expenditure. Households receiving the subsidy appear to decrease their consumption, as seen by the drop to the left of the threshold income. The 2SLS estimation later provide formal evidence that indeed the subsidy has a significant impact on total energy expenditure. Before proceeding any further with the estimation results however, we need to first establish the validity of the RDD, and thereby the appropriateness of using the RDD. 
Figure 2: Types of Energy Expenditure versus Normalized Household Income
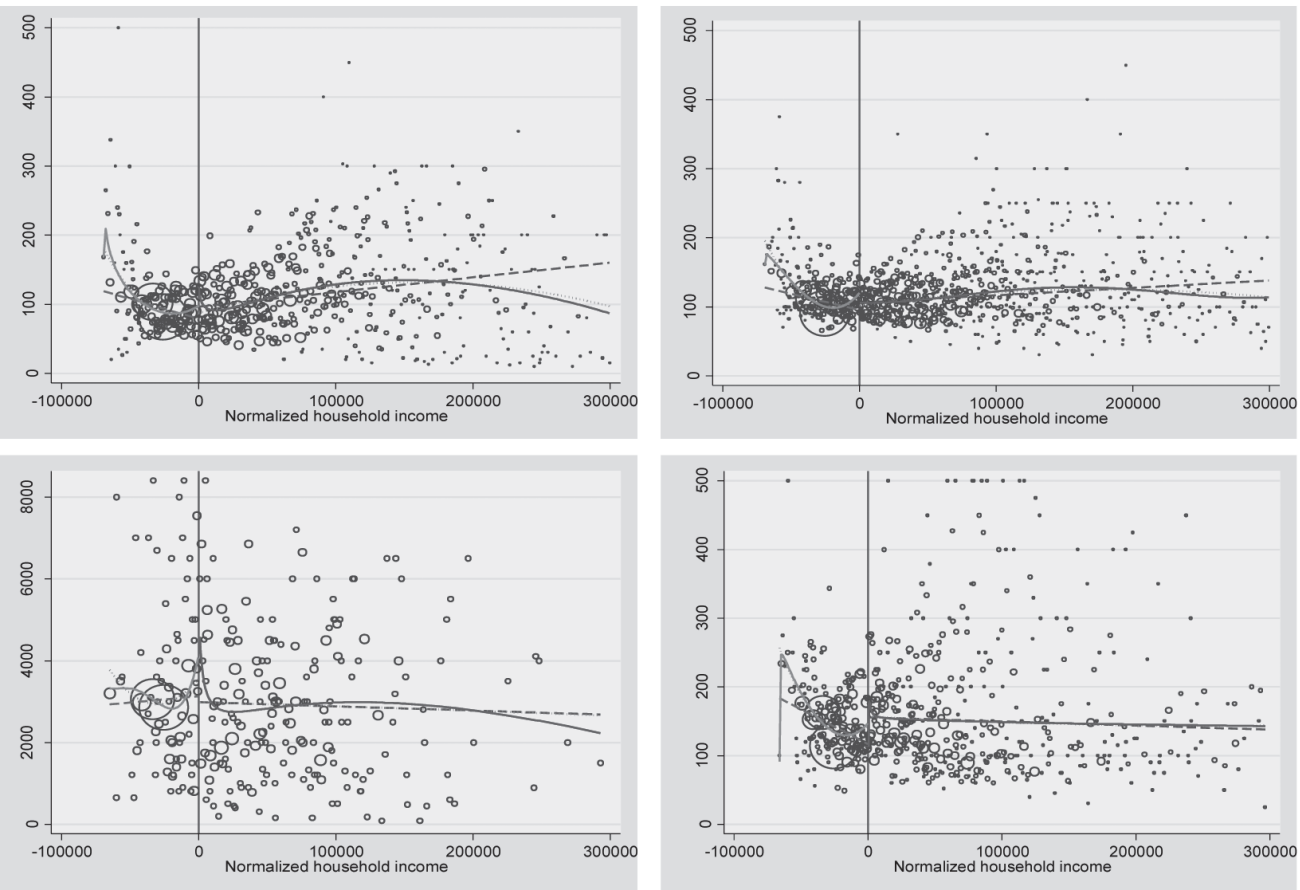

\subsection{RDD Validity Check}

It is imperative to test for the identification assumptions of the RDD and hence the internal validity of the RDD to ensure credible results. The identification strategy adopted here is based on the assumption that eligibility to receive the HEAP subsidy is as good as being randomly assigned in the immediate neighbourhood of the normalized income threshold. This assumption requires the inability of households in precisely manipulating their income as to qualify for the subsidy. If this assumption does not hold, the RDD will be invalid and its results not credible.

The density test developed by McCrary (2008) is a formal test of discontinuity in the density of the assignment variable itself. It tests for manipulation of the assignment variable. The null hypothesis is that there is no discontinuity (no precise control) at threshold of the assignment variable. A rejection of the null hypothesis indicates evidence of endogenous sorting around the assignment variable's threshold, and invalidates the RDD. The density test here is accompanied by a density graph to allow a visual inspection of any jump at the threshold income. A discontinuity or spike to the left of the threshold income suggests income manipulation by the households. Figure 3 indicates no such sign of discontinuity at the normalized threshold, with a discontinuity estimate of 0.0717 and a standard error of 0.0426 . There is no empirical evidence that households precisely manipulate their income to be just below the threshold income in order to be eligible for the HEAP subsidy. 
Figure 3: McCrary Density Test

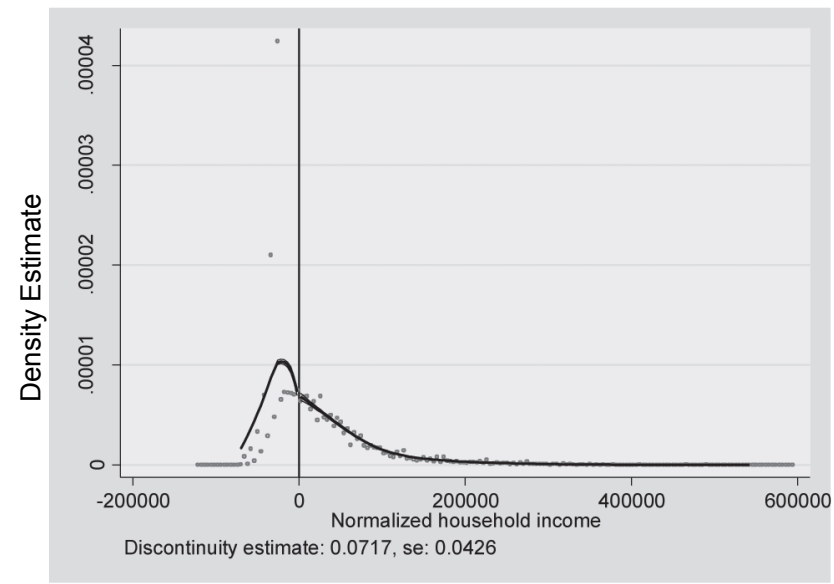

From the validity check here, the RDD appears to be valid and estimation results henceforth obtained should be credible. The following three sections discuss the estimation results: first stage, reduced form, and second stage (IV) results.

\subsection{First stage results: The effects of subsidy eligibility on subsidy receipt}

The first stage results, shown in Table 4, are obtained using OLS estimations. The estimations give the effects of subsidy eligibility on the probability of receiving the HEAP subsidy. As one would expect, eligible households are more likely to receive the subsidy. Indeed here, Specifications (1) to (4) show that, for an eligible household, its probability of receiving the subsidy increases between 2 to 8 percentage points at the threshold. These statistically significant positive coefficients suggest the appropriateness of the eligibility rule in increasing the likelihood of households receiving the subsidy.

Table 4: First Stage Estimations

\begin{tabular}{lcccc}
\hline \multirow{2}{*}{ DV: HEAP receipt } & \multicolumn{4}{c}{ Coefficient for 'Eligibility', $\boldsymbol{Z}$} \\
\cline { 2 - 5 } & $\mathbf{( 1 )}$ & $\mathbf{( 2 )}$ & $\mathbf{( 3 )}$ & $\mathbf{( 4 )}$ \\
\hline$Z$ & $0.084^{* * *}$ & $0.053^{* * *}$ & $0.023^{* * *}$ & $0.024^{* * *}$ \\
& $(0.006)$ & $(0.007)$ & $(0.008)$ & $(0.008)$ \\
F-test for $Z$ & $219.95^{* * *}$ & $51.79^{* * *}$ & $7.41^{* * *}$ & $7.83^{* * *}$ \\
Normalized income & $\checkmark$ & $\checkmark$ & $\checkmark$ & $\checkmark$ \\
(Normalized income) 2 & - & $\checkmark$ & $\checkmark$ & $\checkmark$ \\
(Normalized income) & - & - & $\checkmark$ & $\checkmark$ \\
Covariates/controls & - & - & - & $\checkmark$ \\
$N$ & & & & \\
\hline
\end{tabular}

Notes: Figures in parentheses are standard errors. Significant at the ${ }^{* * *} 1 \%$ level. 
An F-test is used to test for instrument relevance; to test the null hypothesis that subsidy eligibility has no impact on subsidy receipt. The significant F-statistics obtained here suggest that using subsidy eligibility to instrument subsidy receipt is strongly relevant; there is no statistical evidence of weak instrument. The different model specifications in Table 4 serve as a robustness check; it seems that the first stage results here are adequately robust in terms of significance and coefficient sign of the $Z$ instrument.

\subsection{Reduced form results: The effects of subsidy eligibility on energy expenditure}

Table 5 shows that in all specifications, subsidy eligibility has a significant negative effect on total energy expenditure. The Z coefficients here are known as the 'intent-to-treat' (ITT) effects in the program evaluation literature. It measures the average causal effect of subsidy eligibility on energy expenditure for eligible households, regardless of whether or not the households actually receive the subsidy. That is, just by virtue of being eligible, such households see an approximate $8 \%$ to $25 \%$ decrease in their total energy expenditure, at the threshold. From Specification (3), an eligible household see about 12\% decrease in natural gas expenditure, at the threshold. Meanwhile, electricity expenditure of an eligible household decreases between $6 \%$ to $8 \%$. The ITT effects however are inconsequential on miscellaneous energy expenditure.

While the positive effects of eligibility on the probability of receiving subsidy is anticipated, the negative effects of subsidy eligibility and subsidy receipt on energy expenditure as shown in Table 5 are somewhat counterintuitive. This study offers a plausible explanation for these findings. One possible underlying factor driving the negative effects here might be the type of HEAP subsidy a household is eligible for or receives. If a household is eligible for the repair and replacement type of HEAP subsidy, this can reduce its energy expenditure because in order to be eligible for this type, the household's primary heating equipment must have

Table 5: Reduced Form Estimations

\begin{tabular}{|c|c|c|c|c|}
\hline \multirow{2}{*}{$\begin{array}{c}\text { DV: Types of } \\
\text { energy expenditure }(\ln )\end{array}$} & \multicolumn{4}{|c|}{ Coefficient for 'Eligibility', $Z$} \\
\hline & (1) & (2) & (3) & (4) \\
\hline Natural gas & -0.049 & 0.013 & $-0.128 * *$ & -0.069 \\
\hline & $(0.038)$ & $(0.051)$ & $(0.056)$ & $(0.043)$ \\
\hline Electricity & -0.002 & -0.020 & $-0.082 * * *$ & $-0.067 * * *$ \\
\hline & $(0.016)$ & $(0.021)$ & $(0.024)$ & $(0.022)$ \\
\hline Miscellaneous & $\begin{array}{l}-0.018 \\
(0.137)\end{array}$ & $\begin{array}{l}-0.092 \\
(0.189)\end{array}$ & $\begin{array}{l}-0.074 \\
(0.201)\end{array}$ & $\begin{array}{l}-0.110 \\
(0.193)\end{array}$ \\
\hline Total & $\begin{array}{c}-0.075^{* *} \\
(0.031) \\
\end{array}$ & $\begin{array}{c}-0.163^{* * *} * \\
(0.042)\end{array}$ & $\begin{array}{c}-0.256^{* * *} \\
(0.048)\end{array}$ & $\begin{array}{c}-0.210^{* * *} \\
(0.041)\end{array}$ \\
\hline Normalized income & $\checkmark$ & $\checkmark$ & $\checkmark$ & $\checkmark$ \\
\hline$(\text { Normalized income })^{\wedge} 2$ & - & $\checkmark$ & $\checkmark$ & $\checkmark$ \\
\hline$(\text { Normalized income })^{\wedge} 3$ & - & - & $\checkmark$ & $\checkmark$ \\
\hline Covariates/controls & - & - & - & $\checkmark$ \\
\hline
\end{tabular}

Notes: Energy expenditure in natural log. Figures in parentheses are standard errors.

Significant at the $* * * 1 \%$ and $* * 5 \%$ level. 
already been in a defective state. Knowing that the equipment is not working optimally would have prompted the household to decrease its usage and hence a drop in energy expenditure. Households actually receiving this type of subsidy could then have their defective heating equipment replaced with more efficient ones. Using more efficient heating equipment could subsequently contribute to the decrease in energy expenditure. Due to data limitation however, this explanation could not be tested empirically; the 2011 NYCHVS dataset does not have an itemized breakdown of the HEAP subsidy type a household is eligible for or receives. Such itemized data would have enabled a better insight of how the HEAP subsidy is used and its effect on energy expenditure. It remains an important avenue for future work to incorporate data on the type of the HEAP subsidy to actually tease out if the decrease in energy expenditure is indeed because of the shift to using more energy efficient equipment for home heating.

\subsection{Second stage (IV) results: The effects of subsidy receipt on energy expenditure}

Table 6 shows the IV results from the 2SLS estimation of the effects of the HEAP subsidy receipt on energy expenditure, i.e. the effects of interest. The effects given by the IV coefficients here are interpreted as local average treatment effects (LATE), i.e. the average treatment effect for those at the threshold who would be induced to participate by a change in the eligibility status (Z) from 0 to 1 (Wooldridge 2010, p. 953; Lee \& Lemieux 2010, p. 301). The LATE here specifically refers to the compliers, i.e. ineligible households without subsidy, and eligible households with subsidy. The LATE interpretation here is therefore: The impact of the HEAP subsidy on energy expenditures of households that would not have received the subsidy had they been ineligible; when eligible, these households would receive the subsidy and experience an impact in their energy expenditure. To a certain extent, the LATE interpretation limits the generalisation of findings (the external validity), but estimates obtained from a valid RDD have strong internal validity.

Table 6: Second Stage (IV) Estimations

\begin{tabular}{lcccc}
\hline \multicolumn{1}{c}{ DV: Types of } & \multicolumn{4}{c}{ Coefficient for 'HEAP receipt', $\boldsymbol{D}$} \\
\cline { 2 - 5 } energy expenditure $(\boldsymbol{l n})$ & $\mathbf{( 1 )}$ & $\mathbf{( 2 )}$ & $\mathbf{( 3 )}$ & $\mathbf{( 4 )}$ \\
\hline Natural gas & -0.633 & 0.313 & 2.363 & -5.201 \\
& $(0.491)$ & $(1.223)$ & $(2.894)$ & $(6.088)$ \\
Electricity & -0.028 & -0.365 & -0.082 & -3.972 \\
& $(0.185)$ & $(0.374)$ & $(0.674)$ & $(2.586)$ \\
Miscellaneous & -1.722 & 3.876 & -0.083 & 2.074 \\
& $(13.64)$ & $(11.12)$ & $(14.25)$ & $(4.143)$ \\
Total & $-0.757 * *$ & $-0.481 *$ & -5.117 & 2.538 \\
& $(0.334)$ & $(0.282)$ & $(3.322)$ & $(10.31)$ \\
Normalized income & & & & \\
(Normalized income)^2 & - & $\checkmark$ & $\checkmark$ & $\checkmark$ \\
(Normalized income)^3 & - & $\checkmark$ & $\checkmark$ & $\checkmark$ \\
Covariates/controls & - & - & - & $\checkmark$ \\
\hline
\end{tabular}

Notes: Figures in parentheses are standard errors. Significant at the $* * 5 \%$ and $* 10 \%$ level. 
Figure 4: Linear and Quadratic Functions of Total Energy Expenditure
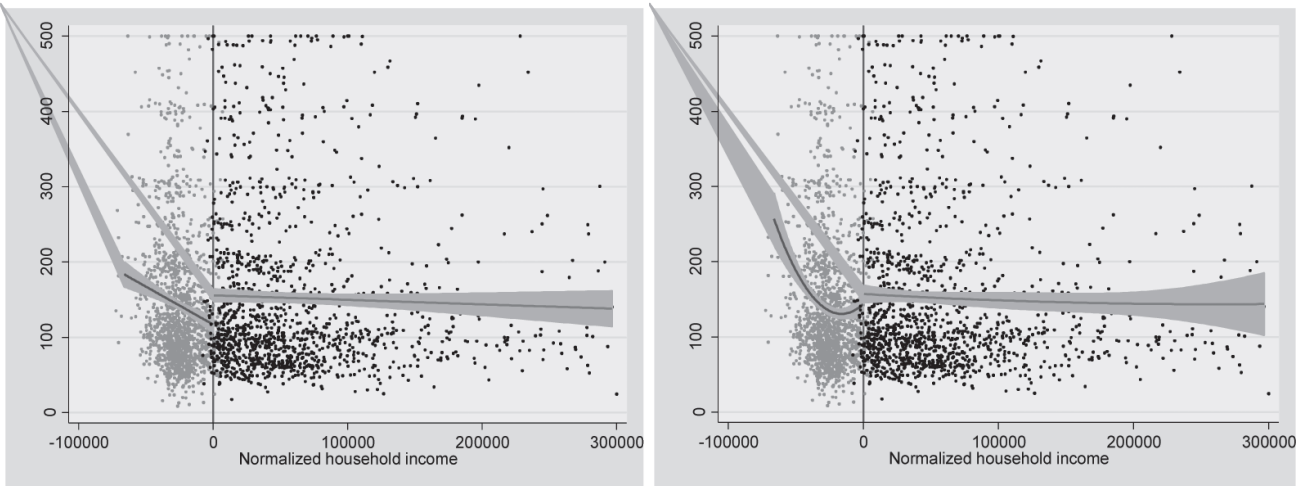

The IV coefficients indicate that at the threshold, households that receive the HEAP subsidy reduce their total energy expenditure by about half (Specification 2) to three-quarters (Specification 1). These significant negative coefficients are consistent with the graphical evidence in Figure 4, where the linear specification sees a larger drop to the left, compared to the smaller drop observed from the quadratic specification. The effects of the HEAP subsidy receipt on natural gas, electricity, and miscellaneous energy expenditure however, are found insignificant. The results here suggest that the HEAP subsidy does have an impact on energy expenditure, although not as strongly (statistically) significant as anticipated and only impacts the total energy expenditure. Any policy implications from these results should be interpreted with caution.

\section{DISCUSSION ON ENERGY SUBSIDY POLICIES}

Results from this study have a number of policy implications. An important finding here is that the HEAP home-heating subsidies can lower households' total energy expenditures. Energy subsidies in developed countries such as the U.S. may be very much different from those in developing countries. Developed countries tend to have energy subsidies in the form of clean renewable energy subsidies in order to promote the usage of such energies (Kalkuhl et al 2013), as well as in the form of subsidies for using energy-efficient 'Energy Star' designated household appliances (Allcott \& Greenstone 2012) and weatherization technologies (Galvin 2010). By lowering the technology investment cost, subsidies in such developed countries tend towards encouraging the adoption of renewable energy and energy-efficient technologies, i.e. such as the use of smart metering systems in some European Union countries (Laicane et al 2014) and feed-in tariffs which is a type of direct subsidy paid by energy suppliers to the consumers when the consumers are able to sufficiently generate their own energy need through for example wind or solar power. As noted by Linares and Labandeira (2010), subsidies for adopting renewable energy technologies can be effective, as such subsidies buffer the high cost of investing in such technologies against the uncertain gains from the investment. Although there are subsidies for adoption of renewable energy in developing countries, for example 
China (Lewis 2010), such subsidies are unable to generate any substantial amount of usage to make any major impact.

Energy subsidies are not limited to just what the developed countries like U.S. is doing with its HEAP subsidies, but (non-oil) energy subsidies are being handed out in other forms especially those being implemented in developing countries such as Gabon, Guatemala, Mozambique, Brazil, and South Africa (Besant-Jones 2006; Heltberg 2003). In these countries, both rural and urban low-income households need only to pay an affordable subsidized monthly (electricity) rate or what is also known as a lifeline rate, up to a certain level of energy consumption. In Kenya, a subsidy programme initiated in 2007 gives out efficient electric bulbs to help reduce household electricity consumption; this programme has since achieved its objective (Mutua \& Kimuyu 2015). Kerosene subsidies are typically given out in other poor countries like India, and Nepal where kerosene is used mostly for cooking and lighting purposes (Shenoy 2010; Kebede 2006; Heltberg 2003). This can help ease the households' financial burdens substantially and elevate their standards of living. The only catch here is the ability to properly identify and differentiate accurately poor households from the non-poor ones. Otherwise, these subsidies would become regressive, where the non-poor households receive a disproportionately larger share of the subsidies and become the main beneficiaries since they are the ones with heavier consumption. Energy subsidies however are not without problems. Kerosene subsidies for example, may also cause supply shortages which in turn restrict access to kerosene (Heltberg 2003), and may result in illegal activities of kerosene adulteration (Lawal 2011). In developing countries especially, removing conventional (non-oil) energy subsidies may be difficult due to the issue of energy affordability among lower-middle income and poor households which are typically the major beneficiaries. In this case, perhaps a better policy strategy is for its gradual phasing-out along with an offset mechanism such as providing monetary incentives to shift to renewable energy use, or adoption of more efficient energy-use technologies.

\section{CONCLUSION}

Using the 2011 NYCHVS data, this paper estimates the causal effects of receiving the HEAP subsidy, i.e. the effects of interest, on different types of energy expenditure. Using the RDD quasi-experimental framework, identification for the causal treatment effect of the HEAP subsidy is achieved by exploiting exogenous variations generated from the HEAP eligibility rule. Results are obtained from three model estimations: first-stage, reduced-form, and second stage (IV) estimations. Results from the IV estimations are the primary interest of this study. The main finding from each of these estimations are: (i) the HEAP subsidy eligibility increases the probability of receiving the HEAP subsidy, (ii) subsidy eligibility decreases energy expenditure, and (iii) subsidy receipt decreases energy expenditure. For an eligible household, its probability of receiving the subsidy increases between 2 to 8 percentage points at the threshold. Just by virtue of being eligible, such households see an approximate $8 \%$ to $25 \%$ decrease in their total energy expenditure at the threshold. Households that receive the HEAP subsidy reduce their total energy expenditure by about half to three-quarters at the threshold.

From the findings of this paper and the discussion on energy subsidy policies, perhaps the best conclusion this paper could afford is that energy subsidies impact energy expenditure in a 
myriad of ways, depending on a host of factors such as whether such subsidies are implemented in developed or developing countries (since these countries have different institutional setting and level of economic development), the form of subsidy (e.g. if it is a feed-in tariff, direct payment to energy producers, subsidies for renewable energy technology investment, reduced rate of electricity payment, vouchers in exchange of kerosene, the giving out energy-efficient light bulbs), and what the subsidy is subsidizing (e.g. energy cost abatement, investment cost of energy technology installation). Since the scope of this paper is limited to the analysis of how the HEAP subsidy impact residential energy expenditure in a developed country setting, many future studies are needed to look at the different angles raised in energy policy discussions above.

\section{REFERENCES}

Allcott, H., \& Greenstone, M. (2012). Is there an energy efficiency gap? Journal of Economic Perspectives, 26(1), 3-28.

Angrist, J. D., \& Lavy, V. (1999). Using Maimonides' rule to estimate the effect of class size on scholastic achievement. Quarterly Journal of Economics, 114(2), 533-575.

Belloumi, M. (2009). Energy consumption and GDP in Tunisia: Cointegration and causality analysis. Energy Policy, 37(7), 2745-2753.

Besant-Jones, J. E. (2006). Reforming power markets in developing countries: What have we learned? Energy and Mining Sector Board Discussion Paper No. 19.

De La Mata, D. (2012). The effect of Medicaid eligibility on coverage, utilization, and children's health. Health Economics, 21(9), 1061-1079.

Dieckhoner, C. (2012). Does subsidizing investments in energy efficiency reduce energy consumption? Evidence from Germany. Institute of Energy Economics Working Paper No. 12/17.

Dube, I. (2003). Impact of energy subsidies on energy consumption and supply in Zimbabwe. Do the urban poor really benefit? Energy Policy, 31(15), 1635-1645.

Freund, C., \& Wallich, C. (1997). Public-sector price reforms in transition economies: Who gains? Who loses? The case of household energy prices in Poland. Economic Development and Cultural Change, 46(1), 35-59.

Galvin, R. (2010). Thermal upgrades of existing homes in Germany: The building code, subsidies, and economic efficiency. Energy and Buildings, 42(6), 834-844.

Gangopadhyay, S., Ramaswami, B., \& Wadhwa, W. (2005). Reducing subsidies on household fuels in India: how will it affect the poor? Energy Policy, 33(18), 2326-2336. 
Hahn, J., Todd, P., \& van der Klaauw, W. (2001). Identification and estimation of treatment effects with a regression-discontinuity design. Econometrica, 69(1), 201-209.

Halicioglu, F. (2007). Home electricity demand dynamics in Turkey. Energy Economics, 29(2), 199-210.

Heltberg, R. (2003). Household fuel and energy use in developing countries - A multicountry study. Oil and Gas Policy Division Report. Washington DC: The World Bank.

Holtedahl, P., \& Joutz, F. L. (2004). Home electricity demand in Taiwan. Energy Economics, 26, 201-224.

Imbens, G. W., \& Wooldridge, J. M. (2009). Recent developments in the econometrics of program evaluation. Journal of Economic Literature, 47(1), 5-86.

Kalkuhl, M., Edenhofer, O., Lessmann, K. (2013). Renewable energy subsidies: Second-best policy or fatal aberration for mitigation? Resource and Energy Economics, 35(3), 217 234.

Kebede, B. (2006). Energy subsidies and costs in urban Ethiopia: The cases of kerosene and electricity. Renewable Energy, 31(13), 2140-2151.

Laicane, I., Blumberga, A., Rosa, M., \& Blumberga, D. (2014). Determinants of household electricity consumption savings: A Latvian case study. Agronomy Research, 12(2), 527542.

Lawal, Y. O. (2011). Kerosene adulteration in Nigeria: Causes and effects. American Journal of Social and Management Sciences, 2(4), 371-376.

Lee, D. S., \& Lemieux, T. (2010). Regression discontinuity designs in economics. Journal of Economic Literature, 48(2), 281-355.

Lewis, J. I. (2010). The evolving role of carbon finance in promoting renewable energy development in China. Energy Policy, 38(6), 2875-2886.

Li, F., Song, Z., \& Liu, W. (2014). China's energy consumption under the global economic crisis: Decomposition and sectoral analysis. Energy Policy, 64(1), 193-202.

Lin, B., \& Jiang, Z. (2011). Estimates of energy subsidies in China and impact of energy subsidy reform. Energy Economics, 33(2), 273-283.

Lin, B., \& Li, A. (2012). Impacts of removing fossil fuel subsidies on China: How large and how to mitigate? Energy, 44(1), 741-749. 
Linares, P., \& Labandeira, X. (2010). Energy efficiency: Economics and policy. Journal of Economic Surveys, 24(3), 573-592.

McCrary, J. (2008). Manipulation of the running variable in the regression discontinuity design: A density test. Journal of Econometrics, 142(2), 698-714.

Mozumder, P., \& Marathe, A. (2007). Causality relationship between electricity consumption and GDP in Bangladesh. Energy Policy, 35(1), 395-402.

Mutua, J., \& Kimuyu, P. (2015). Household energy conservation in Kenya: Estimating the drivers and possible savings. Environment for Development Discussion Paper Series EfD DP 15-04.

Olivia, S., \& Gibson, J. (2008). Household energy demand and the equity and efficiency aspects of subsidy reform in Indonesia. The Energy Journal, 29(1), 21-39.

Rao, N. D. (2012). Kerosene subsidies in India: When energy policy fails as social policy. Energy for Sustainable Development, 16(1), 35-43.

Saboohi, Y. (2001). An evaluation of the impact of reducing energy subsidies on living expenses of households. Energy Policy, 29(3), 245-252.

Shenoy, B. V. (2010). Lessons learned from attempts to reform India's kerosene subsidy. Geneva, Switzerland: International Institute for Sustainable Development (IISD).

U.S. Energy Information Administration (EIA). (2011). Direct federal financial interventions and subsidies in energy in fiscal year 2010. Washington DC: U.S. Department of Energy.

Wooldridge, J. M. (2010). Econometric analysis of cross section and panel data, 2nd ed. Massachusetts: MIT Press.

Yuan, C., Liu, S., \& Wu, J. (2010). The relationship among energy prices and energy consumption in China. Energy Policy, 38(1), 197-207. 